\title{
Development of a new formulation for direct compression of a natural product
}

Melissa Maltais ${ }^{1 *}$, Ricardo Vargas $^{1+}$ and Therese DiPaolo ${ }^{2 \dagger}$

*Correspondence: melissamaltais6@gmail.com

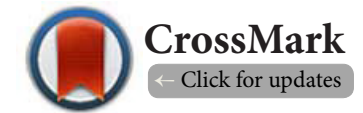

'These authors contributed equally to this work.

'Department of Pharmaceutics and Analytics, Purdue Pharma, 575 Granite Court, Pickering, Ontario, Canada.

${ }^{2}$ Faculty of Pharmacy, University Laval, Pavillon Ferdinand-Vandry, 1050 Avenue of Medicine, Quebec, Canada.

\begin{abstract}
This research project consisted in developing a new formulation for the direct compression of senna -an intrinsically non-compressible material originating from the dried pods of a plant named Cassia acutifolia. The challenge of finding adequate excipients to compress senna was combined to the challenge of maintaining similar weight and appearance to that of the currently marketed senna tablets. These challenges stemmed from the fact that the current formulation is composed of $80 \%$ senna, which created significant limitation for introducing compressible excipients. To overcome these challenges, currently marketed senna tablets are generally manufactured through wet granulation prior to compression, a process that is rather laborious and costly. The water acts as a binder in the granulation process, which allows the tablets to maintain their strength and integrity. However, wetting, drying and testing the granules for assay involves considerable time, labor and machinery as compared to the direct compression process. In addition to cost savings, direct compression does not require water or heat in the process, which could potentially reduce hydrolysis and oxidation of the active principle and enhance product stability. The development of senna formulation for direct compression was conducted in six experimental designs, where batches of senna tablets were manufactured as per specific matrices and analyzed for hardness, friability, disintegration, appearance, average weight, moisture and assay, as the project progressed. The results were compared to defined specifications which were based on the currently marketed senna tablets. A new formulation was found in the sixth experimental design, where optimal levels of hydroxypropyl cellulose, hydroxyethyl cellulose, lactose and croscarmellose sodium were identified. Tablet properties emerging from this formulation met all defined specifications at the time of manufacture and also after one month, three months and six months accelerated stability conducted as per the International Conference on Harmonisation guidelines. In conclusion of this project, a successful formulation for the direct compression of senna was discovered through "Design of Experiments" and "Quality by Design" methodologies. Furthermore, this efficient approach could be used again to develop other formulation presenting similar challenges and could potentially accelerate product launch in prospective pharmaceutical markets.
\end{abstract}

Keywords: Development, formulation, direct compression, design of experiment, quality by design

\section{Introduction}

The objective of this research project was to develop a new formulation for the direct compression of senna - an intrinsically non-compressible powder that originates from the dried pods of a Middle Eastern plant named Cassia acutifolia - known for centuries in the treatment of occasional constipation [1]. The active principles found in senna powder are called sen- nosides and produce therapeutic effect via irritation of the inner layer of the gastro-intestinal tract, therefore activating bowel movements [2]. Absorption of senna through the cells demonstrates linear and positive results shown by Waltenberger et al. [3]. However, absorption is not absolutely required as the therapeutic effect is produced by the sole presence of senna in the gastro-intestinal tract [2]. A consistent demand for the

(c) 2015 Maltais et al; licensee Herbert Publications Ltd. This is an Open Access article distributed under the terms of Creative Commons Attribution License (http://creativecommons.org/licenses/by/3.0). This permits unrestricted use, distribution, and reproduction in any medium, provided the original work is properly cited. 
natural source senna tablets stems from various communities such as the elders, adults, pregnant women and children who suffer from occasional constipation. Senna tablets have been extensively described in Pharmacopeias, Compendium of Pharmaceutical Specialties and the Merck Index and continue to find a competitive advantage over products from synthetic sources such as bisacodyl and docusate sodium that offer similar treatment [1,4-6].

In spite of the abundance of available information on senna tablets, the general manufacturing process remains laborious and costly. Wet granulation prior to compression is generally required due to the non-compressible nature of senna powder. The water used in the process helps creating hydrogen bonding within the tablets matrix, providing mechanical strength and integrity as a result. A considerable benefit of changing the manufacturing process from wet granulation to direct compression was to generate substantial cost savings in terms of process time, labor and machinery requirements. Another major benefit of direct compression is that water and heat are not required in the process which could potentially enhance stability of the finished product by reducing hydrolysis and oxidation of sennosides [7]. The challenge of finding adequate excipients to directly compress senna powder was combined to the challenge of maintaining similar weight and appearance to that of the currently marketed senna tablets. Since senna powder occupies approximately $80 \%$ of the formulation, there was a considerable limitation for introducing compressible excipients without increasing tablet weight. Despite these challenges, it was hypothesized that a new formulation for the direct compression of senna would be discovered through "Design of Experiments" and "Quality by Design" methodologies [8].

\section{Materials and methods Materials}

Eleven excipients were selected based on their organic properties, particle size, density, compressibility, flowability, mode of compression and water solubility in order to optimize powder compatibility, blend uniformity, tablet appearance, tablet weight, tablet hardness, tablet friability and tablet disintegration [9-16]. A mixture of excipients commonly used as binders, diluents, fillers, disintegrant and hardness enhancers were purposely selected to achieve these goals. The excipients were acquired from commercial suppliers such as DOW, FMC Biopolymer, Roquette and were labelled $X_{1}$ to $X_{11}$ as follows for design of experiment purposes.

Pregelatinised starch $\left(X_{1}\right)$, microcrystalline cellulose $\left(X_{2}\right)$, lactose monohydrate $\left(X_{3}\right)$, sorbitol $\left(X_{4}\right)$, ethylcellulose $\left(X_{5}\right)$, hydroxyethyl cellulose $\left(X_{6}\right)$, hydroxypropyl cellulose $\left(X_{7}\right)$, methylcellulose $\left(X_{8}\right)$, hydroxypropylmethyl cellulose $\left(X_{9}\right)$, ethylcellulose from a different supplier than $X_{5}\left(X_{10}\right)$ and alginic acid $\left(\mathrm{X}_{11}\right)$.

The following active pharmaceutical ingredient, disintegrant, glidant and lubricant were also used in the formulation, how- ever, their source remain confidential as per manufacturer's requirements: Senna concentrate C.G., croscarmellose sodium, silicon dioxide and magnesium stearate.

\section{Methods \\ Quality by design ( $Q b D)$}

As part of QbD, the "Quality Target Product Profile" (QTPP) shown in Table 1 was established based on the current manufacturer's specifications for senna tablets. The QTPP was used as a guide to create a similar product profile to achieve similar therapeutic effect.

\section{Design of experiments (DOE)}

In order to find a new formulation for the direct compression of senna, several experiments with different combinations of excipients were attempted. The first set of experiments was conducted as per the Plackett-Burman design shown in Table 2 [17]. The Plackett-Burman design used in this first set of experiments was randomized by Minitab ${ }^{\oplus}$ software.

The Plackett-Burman design, which involved twelve experiments, eleven variables and two levels, was used to screen the excipients that would promote feasibility of the direct compression process. Results for tablet hardness and number of tablets produced from the twelve batches were statistically analyzed through Minitab ${ }^{\circledR}$ software, allowing the formulator to identify the excipients that would promote tablet strength and reasonable productivity [18]. Based on the software analysis, five excipients were retained for further trials.

The second set of experiments was conducted as per the half-factorial experimental design shown in Table 3 [19].

The half-factorial design, which involved seventeen experiments, five variables, two levels and one center point, was used to further analyze the five excipients selected from the Plackett-Burman design. Results for tablet hardness, friability,

Table 1. Quality target product profile.

\begin{tabular}{lll}
\hline Tests & Test methods & Specifications \\
\hline Tablet assay & $\begin{array}{l}\text { High Performance Liquid } \\
\text { Chromatography } \\
\text { USP }<621>\end{array}$ & $90-110 \%$ \\
\hline Tablet moisture & $\begin{array}{l}\text { Moisture Analyzer } \\
\text { (Metler Toledo's }\end{array}$ & $\leq 6 \%$ \\
& Operating Manual) & \\
\hline Tablet hardness & $\begin{array}{l}\text { Hardness Tester } \\
\text { USP }<1217>\end{array}$ & Average: \\
& & Individuals: \\
& {$[3.0-8.0] \mathrm{Kp}$} \\
\hline Tablet friability & $\begin{array}{l}\text { Friability Tester } \\
\text { USP }<1216>\end{array}$ & $\leq 1 \%$ \\
\hline $\begin{array}{l}\text { Tablet disintegration } \\
\text { time }\end{array}$ & $\begin{array}{l}\text { Disintegration Tester } \\
\text { USP }<701>\end{array}$ & $\leq 45$ min. \\
\hline Tablet appearance & Visual & Round Brown \\
& & Biconvex \\
\hline Average tablet weight & Analytical Balance & 289.4 mg $\pm 5 \%$ \\
\hline
\end{tabular}


Table 2. Plackett-Burman experimental design with 11 variables and 2 levels.

\begin{tabular}{llllllllllll}
\hline Experiment \# & $\mathrm{X}_{1}$ & $\mathrm{X}_{2}$ & $\mathrm{X}_{3}$ & $\mathrm{X}_{4}$ & $\mathrm{X}_{5}$ & $\mathrm{X}_{6}$ & $\mathrm{X}_{7}$ & $\mathrm{X}_{8}$ & $\mathrm{X}_{9}$ & $\mathrm{X}_{10}$ & $\mathrm{X}_{11}$ \\
\hline 1 & + & - & - & - & + & + & + & - & + & + & - \\
2 & + & + & - & + & - & - & - & + & + & + & - \\
3 & - & + & + & + & - & + & + & - & + & - & - \\
4 & + & - & + & - & - & - & + & + & + & - & + \\
5 & - & + & - & - & - & + & + & + & - & + & + \\
6 & + & + & - & + & + & - & + & - & - & - & + \\
7 & - & - & - & - & - & - & - & - & - & - & - \\
8 & + & - & + & + & - & + & - & - & - & + & + \\
9 & - & - & + & + & + & - & + & + & - & + & - \\
10 & - & - & - & + & + & + & - & + & + & - & + \\
11 & - & + & + & - & + & - & - & - & + & + & + \\
12 & + & + & + & - & + & + & - & + & - & - & - \\
\hline
\end{tabular}

*Presence of excipients is identified by “ + ".

$\dagger$ Absence of excipients is identified by “-”.

Table 3. Half-Factorial experimental design with 5 variables, 2 vevels and 1 center point.

\begin{tabular}{llllll}
\hline Experiment \# & $\mathbf{X}_{7}$ & $\mathbf{X}_{6}$ & $\mathbf{X}_{8}$ & $\mathbf{X}_{3}$ & $\mathbf{X}_{4}$ \\
\hline 13 & + & - & + & - & + \\
14 & + & - & - & + & + \\
15 & + & + & - & - & + \\
16 & - & - & + & - & - \\
17 & - & + & - & - & - \\
18 & - & + & + & + & - \\
19 & - & - & + & + & + \\
20 & + & - & + & + & - \\
21 & + & + & - & + & - \\
22 & + & - & - & - & - \\
23 & - & + & - & + & + \\
24 & - & + & + & - & + \\
25 & - & - & - & - & + \\
26 & + & + & + & - & - \\
27 & 0 & 0 & 0 & 0 & 0 \\
28 & - & - & - & + & - \\
29 & + & + & + & + & + \\
\hline
\end{tabular}

*Presence of excipients is identified by " + ".

$\dagger$ Absence of excipients is identified by “-”.

\#Intermediate level between presence and absence of excipients is identified by " 0 ".

disintegration time and average weight from the seventeen batches were statistically analyzed through Minitab ${ }^{\oplus}$ software, once again allowing the formulator to further identify the excipients that would produce desired effects on tablets properties. Based on the software analysis, four excipients were retained for further trials and one was eliminated due to the lack of beneficial effect demonstrated on the tablet properties when that particular excipient was added to the formulation.

Subsequent designs of experiments were conducted using reduced and full factorial experimental designs with two variables as shown in Table 4.

Reduced and full factorial DOE were used to pursue optimization of excipient levels in the new formulation in order to produce a finished product that met all specifications outlined in the QTPP.

\section{Manufacturing process}

The same manufacturing process and batch size were used within each DOE in order to minimize variations within batches. In order to adequately assess the behavior of larger powder blends in the equipment, batch sizes between DOE were gradually increased from 50 grams (g) to $500 \mathrm{~g}$ from the Plackett-Burman design to the half-factorial design and then again to 1 kilogram for the four subsequent DOE. Blending of ingredients was performed manually for two minutes by tumbling in polyethylene bags for the twelve experiments of the Plackett-Burman design, then automatically with a mini $\mathrm{V}$-Blender at 30 rotation per minute (rpm) for 20 minutes for the seventeen experiments of the half-factorial design, and then with an 18 litres capacity V-Blender at $50 \mathrm{rpm}$ for 50 minutes for all subsequent experiments. Lubricant blending was performed for a duration of $5 \%$ of the total blending time used in each respective design prior to tabletting with the automated Fette Press 1200i [Leitz Metalworking Technology Group, Fette compacting Rockaway, NJ. Fette tablet press operator training manual 1200i \#683, 2009, 1-91].

\section{Analytical testing}

Equipment such as analytical balance, flow meter [20], hardness tester, friability tester, disintegration tester, moisture balance and HPLC system [21] were used in accordance to the settings specified in the United States Pharmacopeia [22], operating manuals and internal validated methods. Hardness and friability were measured to ensure mechanical strength of the finished product, whereas assay and tablet moisture were performed to assess degradation of the sennosides and identify a potential correlation with moisture uptake over time. With regards to dissolution, this test was not required for senna tablets since dissolution and absorption of sennosides through the cell are not involved in producing therapeutic effect. For this product, the emphasis was placed on achieving adequate disintegration time since the presence of senna particles is required to produce peristaltism via irritation of the inner wall of the intestine.

\section{Product stability}

The new product was also subjected to an accelerated stability study as per the International Conference of Harmonization (ICH) guidelines [23] in order to assess product stability at 
Table 4. Reduced and full factorial experimental designs with attempted excipient levels.

\begin{tabular}{|c|c|c|c|c|c|}
\hline \multicolumn{6}{|c|}{ Excipient Levels (mg/tablet) } \\
\hline Type of Design & $\begin{array}{l}\text { Experiment } \\
\#\end{array}$ & $\begin{array}{l}\text { Hydroxypropyl } \\
\text { cellulose }\end{array}$ & $\begin{array}{l}\text { Hydroxyethyl } \\
\text { cellulose }\end{array}$ & Lactose & $\begin{array}{l}\text { Croscarmellose } \\
\text { sodium }\end{array}$ \\
\hline \multirow{4}{*}{$\begin{array}{l}\text { Reduced Design } \\
\text { with } 2 \text { Variables }\end{array}$} & 30 & 15 & \multirow{4}{*}{$\begin{array}{l}\text { *Present, } \\
\text { but not used as } \\
\text { a variable in this } \\
\text { design }\end{array}$} & 15 & \multirow{4}{*}{$\begin{array}{l}{ }^{\dagger} \text { Present, } \\
\text { but not used as } \\
\text { a variable in this } \\
\text { design }\end{array}$} \\
\hline & 31 & 5 & & 35 & \\
\hline & 32 & 15 & & 25 & \\
\hline & 33 & 5 & & 20 & \\
\hline \multirow{2}{*}{$\begin{array}{l}\text { Full Design with } \\
2 \text { Variables }\end{array}$} & 34 & 20 & 5 & \multirow{2}{*}{\multicolumn{2}{|c|}{$\begin{array}{l}{ }^{\ddagger} \text { Present, but not used as } \\
\text { a variable in this design }\end{array}$}} \\
\hline & 35 & 20 & 10 & & \\
\hline \multirow{2}{*}{$\begin{array}{l}\text { Reduced Design } \\
\text { with } 2 \text { Variables }\end{array}$} & 36 & 5 & 15 & \multirow{2}{*}{\multicolumn{2}{|c|}{$\begin{array}{l}{ }^{5} \text { Present, but not used as } \\
\text { a variable in this design }\end{array}$}} \\
\hline & 37 & 10 & 10 & & \\
\hline \multirow{4}{*}{$\begin{array}{l}\text { Full Design with } \\
2 \text { Variables }\end{array}$} & 38 & \multirow{4}{*}{\multicolumn{2}{|c|}{$\begin{array}{l}\text { 'Present, but not used as } \\
\text { a variable in this design } \\
20 \\
30 \\
30\end{array}$}} & 20 & 13.5 \\
\hline & 39 & & & 27 & -- \\
\hline & 40 & & & 13.5 & -- \\
\hline & 41 & & & 27 & -- \\
\hline
\end{tabular}

${ }^{\star}$ Hydroxyethyl cellulosewasused in experiment \#33 only, at $15 \mathrm{mg} /$ tablet, in order to acquire additional information onits possible effect on tablet appearance enhancement.

$\dagger$ Croscarmellose sodium was used at the same level ( $5.1 \mathrm{mg} / \mathrm{tablet})$ in experiments \#30 to \#33.

‡ Lactose was used at $10 \mathrm{mg} /$ tablet and $15 \mathrm{mg} /$ tablet in experiments \#34 and \#35, respectively, in order to equilibrate the tablet weight between experiments, whereascroscarmellose sodium was used at the same level ( $8.5 \mathrm{mg} / \mathrm{tablet})$ in both experiments \#34 and \#35.

\$Lactose and croscarmellose sodium were used in $20 \mathrm{mg} /$ tablet and $13.5 \mathrm{mg} /$ tabletin experiments \#36 and \#37, respectively.

$\|$ Hydroxypropyl cellulose and hydroxyethyl cellulose were each used at the same levels $(10 \mathrm{mg} / \mathrm{tablet})$ in experiments \#38 to 41 .

extreme conditions $-40^{\circ} \mathrm{C}$ and $75 \%$ relative humidity (RH). Three samples of 100 tablets were packaged in high density polyethylene (HDPE) bottles with induction sealed caps and placed in an environmental stability chamber at $40^{\circ} \mathrm{C}$ and $75 \%$ $\mathrm{RH}$. One sample bottle was removed from the chamber after one month, three months and six months exposure periods, and tested for assay and tablet moisture.

\section{Results and discussion}

Upon completion of the six DOE conducted as described in "Methods", a new formulation was found with the excipient levels described in Table 5.

In the first set of experiment conducted as per the PlackettBurman design matrix, five critical excipients were selected for further trials: lactose monohydrate, sorbitol, hydroxypropyl cellulose, hydroxyethyl cellulose and methyl cellulose.
In the second set of experiments conducted as per the halffactorial design, methyl cellulose was eliminated from further trials since no desired effect was observed on tablet properties when this particular excipient was present in the formulation. On the other hand, lactose monohydrate, sorbitol, hydroxypropyl cellulose and hydroxyethyl cellulose were retained for further trials.

In the four subsequent DOE, optimal tablet hardness and friability responses were observed with $5 \mathrm{mg}$ sorbitol and $10 \mathrm{mg}$ hydroxypropyl cellulose per tablet, whereas adequate tablet disintegration time was observed with $30 \mathrm{mg}$ lactose and 13.5 $\mathrm{mg}$ croscarmellose sodium per tablet, respectively. In terms of average tablet weight and tablet appearance, these properties were enhanced with the presence of $10 \mathrm{mg}$ hydroxyethyl cellulose per tablet. Hydroxyethyl cellulose also seemed to promote smoother compression runs with no interruption.

Table 5. Optimal levels of selected excipients in the new formulation.

\begin{tabular}{lllll}
\hline $\begin{array}{l}\text { Senna } \\
\text { (Active ingredient) }\end{array}$ & Selected excipient & Role of excipient & Affected response & Optimal level \\
\hline $215 \mathrm{mg} /$ tablet & Sorbitol & Hardness enhancer & Hardness and Friability & $5 \mathrm{mg} /$ tablet \\
& Hydroxypropyl cellulose & Binder & & $10 \mathrm{mg} / \mathrm{tablet}$ \\
& Lactose & Disintegration enhancer & Disintegration Time & $30 \mathrm{mg} / \mathrm{tablet}$ \\
& Croscarmellose sodium & Disintegrant & & $13.5 \mathrm{mg} / \mathrm{tablet}$ \\
& Hydroxyethyl cellulose & $\begin{array}{l}\text { Binder and Appearance } \\
\text { Enhancer }\end{array}$ & Tablet Appearance & $10 \mathrm{mg} / \mathrm{tablet}$ \\
\hline
\end{tabular}


In the course of the sixth DOE, the tablets produced from experiment \#40 demonstrated the following results for assay, moisture, hardness, friability disintegration, appearance and average weight:

- Assay: $108.5 \%$

- Tablet Moisture: $4.79 \%$

- Hardness: 4.6 Kilopond (Kp)

- Friability: $0.33 \%$

- Disintegration Time: 31 minutes

- Appearance: Round Brown Biconvex

- Average Tablet Weight: $294.9 \mathrm{mg}$

- Stability results at initial, 1 month, 3 months and 6 months exposure periods at $40^{\circ} \mathrm{C} / 75 \% \mathrm{RH}$ :

Assay: 108.5\% (Initial); 106.1\% (1 month); $101.0 \%$ (3 months); 91.5\% (6 months).

Tablet Moisture: $4.76 \%$ (Initial); 4.34\% (1 month); 4.57\% (3 months); $4.93 \%$ (6 months).

The above results met all specified limits outlined in the QTPP. Furthermore, stability data also demonstrated values within specifications after one month, three months and six months exposure periods at $40^{\circ} \mathrm{C}$ and $75 \% \mathrm{RH}$. The decrease in assay and increase in tablet moisture are typically observed in current senna formulations during stability studies, which are consistent with the above trends. As a general rule, a 24 months expiry period can be assigned to products that meet all specifications for six months exposure period at accelerated stability conditions [23]. Therefore, the new product shelf life could potentially be suitable for the pharmaceutical market. A brief comparison of the current senna tablet and new senna tablet formulations is shown in Table 6 .

\section{Conclusion}

The power of $\mathrm{QbD}$ and $\mathrm{DOE}$ methodologies were instrumental in the discovery of the new formulation innovated in this research project. This approach allowed the formulator to carefully select the best excipients for the formulation based on statistical analyses performed in a sequential manner. Above and beyond, the six DOE described in this project could be used again to develop other challenging formulations involving large amounts of non-compressible materials.

In addition, the newly formulated senna tablets demonstrated great potential for near future markets since it continues to offer natural properties as compared to other synthetic active pharmaceutical ingredient and formulations $[24,25]$. Therefore, the new product could naturally find a prospective niche in today's pharmaceutical market.

Table 6. Comparison of the current(Left) and new (Right) senna tablet formulations.

\begin{tabular}{|c|c|c|}
\hline Parameters & Current senna formulation & New senna formulation \\
\hline Manufacturing process & Wet Granulation & Direct Compression \\
\hline Active ingredient & Senna & Senna \\
\hline Excipients & $\begin{array}{l}\text { Microcrystalline Cellulose, } \\
\text { Corn Starch, } \\
\text { Magnesium Stearate }\end{array}$ & $\begin{array}{l}\text { Hydroxypropyl cellulose, } \\
\text { Hydroxyethyl cellulose, } \\
\text { Lactose,Sorbitol, Croscarmellose } \\
\text { sodium, Silicone dioxide }(0.5 \%) \text {, } \\
\text { Magnesium stearate }(1.5 \%)\end{array}$ \\
\hline Tablet assay & $90-110 \%$ & $108.5 \%$ \\
\hline Tablet moisture & $\leq 6 \%$ & $4.79 \%$ \\
\hline Tablet hardness & $\begin{array}{l}\text { Conforms to: } \\
\text { Average: }[3.5-7.0] \mathrm{Kp} \\
\text { Individuals: }[3.0-8.0] \mathrm{Kp}\end{array}$ & $\begin{array}{l}\text { Average: } 4.6 \mathrm{Kp} \\
\text { Individuals: [3.1-5.6] Kp }\end{array}$ \\
\hline Tablet friability & $\leq 1 \%$ & $0.33 \%$ \\
\hline Tablet disintegration time & $\begin{array}{l}\leq 45 \text { min. } \\
\text { (Typically } 10 \text { to } 15 \text { minutes) }\end{array}$ & $31 \mathrm{~min}$. \\
\hline Tablet appearance & Round Brown Biconvex & Round Brown Biconvex \\
\hline Average tablet weight & Typically $260 \mathrm{mg}$ & $289.4 \mathrm{mg}$ \\
\hline
\end{tabular}

Tablet Image

(Left: Current Senna Tablet)

(Right: New Senna Tablet)

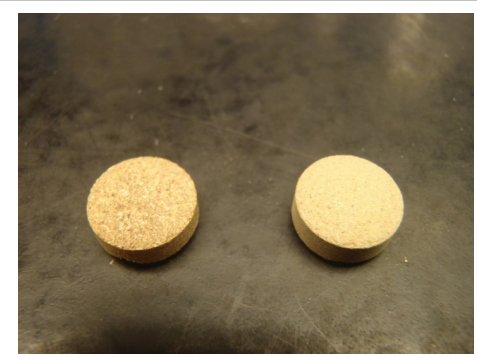




\section{Additional files}

\section{Supplementary table}

\section{Competing interests}

The authors declare that they have no competing interests.

\section{Authors' contributions}

\begin{tabular}{|l|c|c|c|}
\hline Authors' contributions & MM & RV & TD \\
\hline Research concept and design & $\checkmark$ & $\checkmark$ & -- \\
\hline Collection and/or assembly of data & $\checkmark$ & $\checkmark$ & $\checkmark$ \\
\hline Data analysis and interpretation & $\checkmark$ & $\checkmark$ & -- \\
\hline Writing the article & $\checkmark$ & -- & $\checkmark$ \\
\hline Critical revision of the article & $\checkmark$ & -- & $\checkmark$ \\
\hline Final approval of article & $\checkmark$ & -- & $\checkmark$ \\
\hline Statistical analysis & $\checkmark$ & $\checkmark$ & -- \\
\hline
\end{tabular}

\section{Acknowledgement}

I would like to thank my directors of research Ricardo Vargas and Therese Di Paolo for giving me the opportunity to pursue this Master's degree project within my organisation as part of the Master of pharmaceutical sciences program at the Faculty of Pharmacy of University Laval. I would also like to thank Ashok Goundalkar and Jangshin An for providing me with extensive knowledge and training on manufacturing equipment and analytical methods involved in the manufacturing and testing of senna tablets. Thanks everyone for contributing your valuable time to the accomplishment of this project.

\section{Publication history}

Editors: Robert A. Lodder, University of Kentucky, USA. Jayakanth Kanakala, University of Minnesota, USA. Received: 17-Oct-2015 Final Revised: 28-Nov-2015 Accepted: 04-Dec-2015 Published: 14-Dec-2015

\section{References}

1. O'Neil MJ, Heckelman PE, Koch CB, Roman KJ, Kenny CM and D'Arecca MR. Senna. Merck \& Co., Inc. Whitehouse Station, NJ, USA, Fourteenth Edition (Eds.), The Merck Index 2006, 1459.

2. Rogers Healthcare Group. Senokot Family of Laxatives. Senokot.ca. 2012 I Website

3. Waltenberger B, Avula B, Ganzera M, Khan IA, Stuppner H and Khan SI. Transport of sennosides and sennidines from Cassia angustifolia and Cassia senna across Caco-2 monolayers--an in vitro model for intestinal absorption. Phytomedicine. 2008; 15:373-7. | Article | PubMed

4. Committee of revision. Sennosides Tablets. United States Pharmacopeial Convention Rockville, MD. (Eds.), United States Pharmacopeia and National Formulary. 2008; 3:3230.

5. European Directorate for the quality of medicine and healthcare. Senna Pods, Alexandrian. European Pharmacopeia Commission, Strasbourg, France, Seventh Edition, (Eds). European pharmacopoeia. 2010; 1:1238

6. Canadian Pharmacists Association. Senokot ${ }^{\circledR}$ Preparations. Canadian Pharmacists Association, Ottawa, Ontario (Eds.), Compendium of Pharmaceuticals and specialties. 2011; 2281-2282.

7. Goppel M and Franz G. Stability control of senna leaves and senna extracts. Planta Med. 2004; 70:432-6. | Article I PubMed

8. Betterman SM, Levy SE and Brown BAS. A tale of two drugs: How using QbD tools can enhance the development process. Journal of GXP Compliance. 2012; 16:34-41. | Article

9. Rowe R, Sheskey P and Weller P. Starch Pregelatinized, Cellulose Microcrystalline, Lactose, Sorbitol, Ethylcellulose, Hydroxypropyl
Cellulose, Hydroxyethyl Cellulose, Methylcellulose, Hypromellose, Alginic Acid. London, UK Pharmaceutical Press and Washington, DC American Pharmacists Association Fouth edition (Eds.), Handbook of Pharmaceutical Excipients. 2003: 16-18.

10. U.S. Food and Drud Administration. Generally Recognised as Safe (GRAS). FDA. 2012. | Website

11. Odeku OA. The compaction of pharmaceutical powders. Pharmainfo. 2012. | Article

12. Committee of Revision. Powder Flow $<1174>$. United States Pharmacopeia. 2012. | Website

13. Duchatsch K, Falconet J, Tardy G, Lammens RF and Fretter B. Working with Heckel Plots: Method for checking the plausibility of force displacement data. Pharmatech. 2012. | Pdf

14. Sonnergaard JM. A critical evaluation of the Heckel equation. Int J Pharm. 1999; 193:63-71. I Article I PubMed

15. Agarwal V and Bajpai M. Pharmacognostical and biological studies on senna \& its products: an overview. International Journal of Pharma and Bio Sciences. 2010; 1:1-10. I Pdf

16. Gohel M. Tablet Disintegrants. Pharmainfo. 2013. | Website

17. Plackett RL and Burman JP. Placket-Burman design - Wikipedia. 2012. | Website

18. Ryan BF, Joiner BL and Cryer JD. Two- and three variables Graphs. Duxbury Press Belmont, CA, Fifth edition (Eds.), Minitab ${ }^{\circledR}$ Handbook. 2005; 144-172.

19. Minitab ${ }^{\circledR} 17$ support. Factorial designs, Available 2-level factorial designs. 2013. | Website

20. Paul N. Gardner Company Inc. Flodex ${ }^{\mathrm{TM}}$ Powder Flowability Test Instrument. Gardco. 2012. | Website

21. Kazakevich YV and LoBrutto R. Reversed-Phase HPLC. Hoboken, NJ WileyInterscience (Eds.), HPLC for pharmaceutical scientists. 2007; 139-228.

22. Committee of Revision. High-Pressure Liquid Chromatography <621>, Disintegration $\langle\mathbf{7 0 1}\rangle$, Powder Flow $\langle\mathbf{1 1 7 4}\rangle$, Friability $\langle 1216\rangle$, Hardness $<1217>$. United States Pharmacopeia. 2008; 238-243.

23. ICH Expert Working Group. ICH Harmonised Tripartite Guideline, Stability Testing of New Drug Substances and Products Q1A(R2). ICH 2014. I Pdf

24. Canadian Pharmacists Association. Dulcolax ${ }^{\circledR}$ bisacodyl. Canadian Pharmacists Association, Ottawa, Ontario (Eds.), Compendium of Pharmaceuticals and specialties. 2011; 829-830.

25. Canadian Pharmacists Association. Colace ${ }^{\circledR}$ docusate sodium. Canadian Pharmacists Association, Ottawa, Ontario (Eds.), Compendium of Pharmaceuticals and specialties. 2011; 634.

\section{Citation:}

Maltais M, Vargas R and DiPaolo T. Development of a new formulation for direct compression of a natural product. J Pharm Technol Drug Res. 2015; 4:2. http://dx.doi.org/10.7243/2050-120X-4-2 